\title{
Diálogos com a Educação do Campo: o livro didático em questão
}

Márcio da Costa Berbat ${ }^{1}$, Gabriela de Carvalho Feijó ${ }^{2}$

${ }^{1}$ Universidade Federal do Estado do Rio de Janeiro - UNIRIO. Departamento de Didática. Avenida Pasteur 458, Urca, Rio de Janeiro - RJ. Brasil. marcioberbat@yahoo.com.br. ${ }^{2}$ Universidade Federal do Estado do Rio de Janeiro - UNIRIO.

RESUMO. Este artigo tem como objetivo compreender a relevância do livro didático do campo no cotidiano da Escola Municipal Santa Luzia. Foram propostos dois objetivos específicos: a) caracterizar o movimento de educação do campo; b) caracterizar e analisar a política pública do livro didático do campo, que foram contemplados pela análise bibliográfica e pelo Estudo de Caso. Buscou-se, nesse sentido, contextualizar a educação do campo, a partir das lutas dos movimentos sociais do campo em favor de uma escola que favoreça a identidade e conquista de direitos do homem do campo; buscou-se, também, contextualizar o Programa Nacional do Livro Didático do Campo (PNLD Campo) de modo a entender à realidade do campo brasileiro. Por fim, o levantamento de dados sobre as experiências de alunos e professores, comparando-os com as considerações formuladas a partir de algumas referências teóricas. Esse trabalho permitiu perceber que apesar do PNLD Campo ter como objetivo distribuir obras que atendam a especificidade do campo, a partir do contexto pesquisado, algumas obras não consideram a organização multisseriada, nem se relacionam de forma pertinente ao contexto camponês nas suas lutas, formas de reprodução da existência, identidade e cultura.

Palavras-chave: Livro Didático, Educação do Campo, PNLD Campo. 


\title{
Dialogues with Rural Education: the course book in question
}

\begin{abstract}
This article aims at understanding the relevance of the rural course book in the daily life of Santa Luzia Municipal School. Two specific purposes were settled: a) to characterize the dynamics of rural education; b) to characterize and analyze the public policy for course books in the countryside, which profited from bibliographical analysis and case study. It was intended, therefore, to contextualize rural education in social movements' fights for a school that contributes to the countrymen's identity and rights' conquest; this article was also intended to contextualize the Countryside National Course Book Program (PNLD Rural, in Portuguese) in order to better understand the reality of the Brazilian countryside; lastly, there was a data survey about students' and teachers' experiences, comparing them to the reflexions on some theoretic references. This research showed that, despite the fact that PNLD Rural aims at handing out books that suit the countryside's specificity, some works do not take into account the multigrade organization in place or do not relate, in a relevant way, to the countrymen in their struggles with perpetuation of identity and culture.
\end{abstract}

Keywords: Course Book, Rural Education, PNLD Rural. 


\section{Diálogo con el Educación del Campo: libro de enseñanza en pregunta}

RESUMEN. Este artículo tiene como objetivo comprender la importancia de enseñar el libro de texto en la vida diaria de la Escuela de Santa Luzia. Se propusieron tres objetivos específicos: a) caracterizar el movimiento de educación rural; b) caracterizar la política pública del libro de educación rural de la enseñanza; c) analizar la política pública del libro de educación rural de la enseñanza, que fueron cubiertos por la revisión de la literatura y el estudio de caso. Se busca en esta dirección, contextualizar el campo de la educación, de las luchas de los movimientos sociales rurales en favor de una escuela que favorece la identidad y la conquista de la esfera de los derechos humanos. También trató de contextualizar el Programa Nacional de Didáctica libro Rural (campo PNLD) con el fin de comprender la realidad brasileña campo. Por último, los datos de la encuesta sobre las experiencias de los estudiantes y profesores, comparándolas con las consideraciones formulado a partir de algunas reflexiones teóricas. Este trabajo permitió darse cuenta de que a pesar del campo PNLD tienen como objetivo distribuir trabajos que cumplan con la especificidad del campo, y desde el contexto investigado, algunas obras no consideran organización multigrado, ni se relaciona de una manera significativa al contexto campesino en sus luchas, formas de reproducción de la existencia, la identidad y la cultura.

Palabras-clave: Libros de Texto, Educación del Campo, Campo PNLD. 


\section{Introdução}

A presente pesquisa é fruto das reflexões e análises desenvolvidas com o livro didático na Educação do Campo a partir do programa "Território e Trabalho para a Educação a Distância", com bolsas de iniciação científica e desenvolvido no curso de licenciatura em Pedagogia a distância no contexto da Educação do Campo, que tem como título de pesquisa: Territorialidade(S) e Cultura(S): Espaço, Tempo e Aspectos Linguísticos nos Primeiros Anos da Educação Básica e integrado ao Trabalho de Conclusão de Curso de Licenciatura em Pedagogia de vários discentes da Universidade Federal do Estado do Rio de Janeiro (UNIRIO).

O tema "Educação do Campo" tem ganhado visibilidade nas políticas públicas e nos centros de formação docente, levando-nos a refletir sobre os descasos e conquistas dessa forma de educação com respeito às singularidades de uma parcela importante da sociedade brasileira. Intencionando conhecer melhor o que é a Educação do Campo, seu desdobramento no contexto real de uma escola em área rural a partir da política pública do livro didático do campo, buscou-se favorecer o aprimoramento do direito de todos com a educação. A Educação do Campo pode ser entendida como a articulação entre a luta por um modelo de desenvolvimento compatível com a vida digna no campo e o acesso à educação de qualidade que atenda a essas demandas. Como morador(es) do campo, podemos potencializar a importância dos estudos ainda no espaços de formação inicial de professores, tencionando os aspectos humanos em busca de uma outra escola e outra educação emancipadora das práticas cotidianas dos sujeitos do campo brasileiro.

Nesse sentido, a Educação do Campo reflete os interesses da classe trabalhadora em favor de uma educação de qualidade para a formação integral da população do campo, estando articulada aos processos culturais e sociais vividos pelos trabalhadores em suas lutas diárias.

Essa articulação do cotidiano dos alunos da chamada zona rural e de suas vivências nos processos de ensino e aprendizagem tem sido norteadores das políticas públicas do governo, dentre elas a produção e distribuição de livros didáticos específicos para o campo.

Buscando

favorecer aprendizagens significativas, a formação para cidadania e o 
desenvolvimento da consciência crítica dos indivíduos do campo para continuarem lutando pela transformação da sociedade, o livro didático do campo já é realidade em muitas escolas do campo brasileiras.

Dentre essas escolas do campo está a Escola Municipal Santa Luzia (Foto 01), localizada na Alameda das Magnólias, $\mathrm{n}^{\circ} 1070$, no bairro Vale das Princesas do município de Miguel Pereira, Estado do Rio de Janeiro, a qual foi objeto de pesquisa no âmbito desse trabalho.

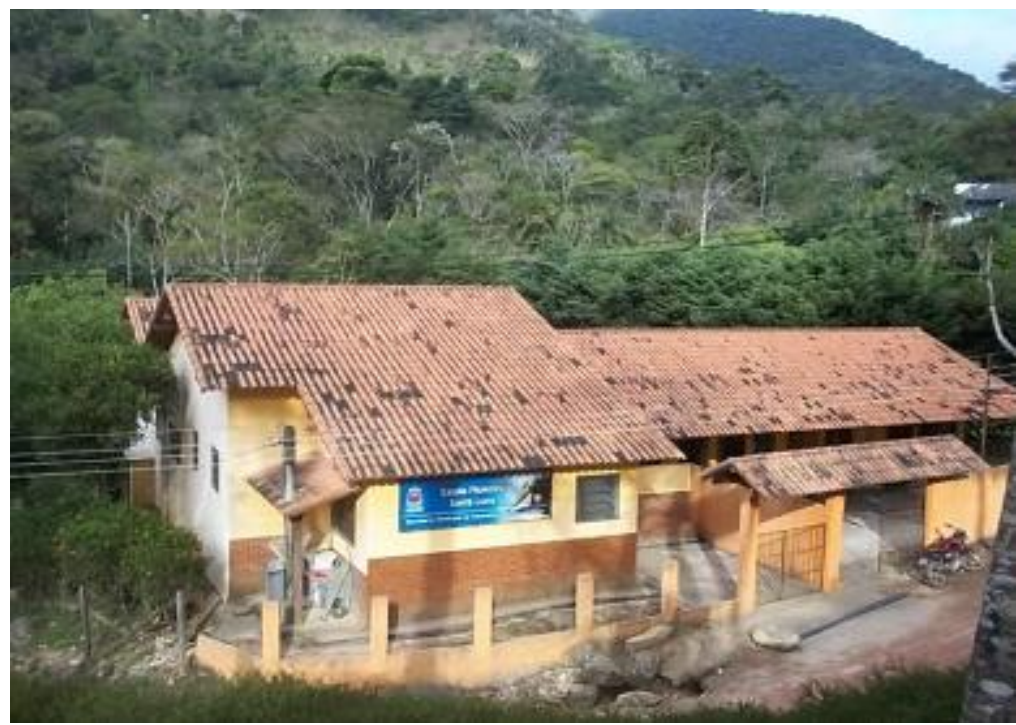

Foto 01 - Vista Frontal da Escola Municipal Santa Luzia. Autores, 2016.

Objetivando identificar a relevância ou não do livro didático do campo em relação à realidade educativa da Escola Municipal Santa Luzia e, levando em conta o espaço cultural e social vivido por seus alunos, definiu-se como objetivos específicos: a) caracterizar o movimento de educação do campo; b) caracterizar a política pública do livro didático do campo; c) analisar a política pública do livro didático do campo. Como metodologia optou-se pela pesquisa bibliográfica e pelo Estudo de Caso Exploratório (Ludke \& André, 2013) na escola mencionada.

Segundo a professora Neusa Lischt Wenchutz Meireles, a Escola Municipal Santa Luzia oferece os anos iniciais do ensino fundamental de forma multisseriada e unidocente, ou seja, as turmas de $2^{\circ}, 3^{\circ}, 4^{\circ}$ e $5^{\circ}$ anos realizam suas aprendizagens ao mesmo tempo e no mesmo espaço contando apenas com uma professora. 
Desde o segundo semestre de 2014, quando a pesquisa teve início, a escola vem apresentando mudanças no número de alunos. Em 2014, eram 10 alunos, no ano seguinte eram $08 \mathrm{e}$ atualmente atende 06 alunos (2016). Sendo assim, os dados dessa pesquisa se baseiam na realidade educativa dessa escola entre o período de agosto de 2014 a agosto de 2016.

Nesse sentido, apresentaremos um breve histórico da Educação do Campo e como ela vem se desenvolvendo no município de Miguel Pereira no Estado do Rio de Janeiro, seguido da análise do Programa Nacional do Livro Didático do Campo (PNLD Campo) e a realidade dos alunos da Escola Municipal Santa Luzia. Finalizamos o texto com as reflexões construídas a partir da pesquisa bibliográfica e da realidade e suas possíveis interpretações com as vivências narrativas no chão da escola.

\section{A Educação do Campo}

Nas últimas décadas a luta pelo direito a educação tem envolvido novos atores. Trata-se de um movimento que tem buscado uma educação de qualidade direcionada a população do campo. Os trabalhadores rurais são os protagonistas dessa reivindicação por uma educação diferenciada, uma
Educação do Campo (Molina \& Freitas, 2011, p. 18).

Segundo Molina e Freitas (2011, p. 18), essa reivindicação foi acrescida a luta pela terra e pelos direitos básicos de desenvolvimento no campo, apresentando-se como uma reação a falta de ações políticas na educação realizada na zona rural e o não atendimento de outros direitos dos camponeses.

Nesse contexto, as lutas dos movimentos sociais do campo contra as contradições do sistema capitalista, buscaram e buscam condições dignas para a manutenção e a reprodução da vida do homem do campo.

Essas condições dignas pressupõem não só o acesso a terra para a reprodução e sustento material, mas, também uma formação que valorize os sujeitos do campo, seus saberes e sua memória.

A Educação do Campo pode ser entendida como a articulação entre a luta por um modelo de desenvolvimento compatível com a vida digna no campo e o acesso à educação de qualidade que atenda a essas demandas.

Segundo Ferreira e Brandão (2011), a história da educação brasileira é perpassada pela discriminação e pela exclusão, não sendo diferente com a 
educação exercida no campo, que vem sendo deixada em segundo plano pelos governantes. Assim, a Educação do Campo nasce do descaso e da forma como o poder público trata à educação no âmbito das escolas em área rural.

As escolas do campo são aquelas que têm sua sede no espaço geográfico classificado pelo IBGE como rural, assim como as identificadas com o campo, mesmo tendo sua sede em áreas consideradas urbanas. Essas últimas são assim consideradas porque atendem a populações de municípios cuja produção econômica, social e cultural está majoritariamente vinculada ao campo (Henriques, 2007, p. 14).

Nesse sentido, a Educação do Campo surge como oposição a projetos educativos que visão a instrumentalização para o modo de produção capitalista, que sempre determinou a "educação rural" (Druzian $\&$ Meuer, 2013) e ainda com a:

A preocupação na época não era de que a educação fosse para todos e de que os camponeses fossem atendidos no direito à educação. $\mathrm{O}$ desenvolvimento industrial era o "carro chefe", apontando diretrizes às escolas primárias em propriedades rurais que seriam aproveitadas posteriormente nas indústrias instaladas nas cidades. (Ferreira \& Brandão, 2011, p. 8).
Busca-se, através desse novo modelo de educação, superar a incoerência entre a educação oferecida aos alunos do campo e suas vivências, além do comprometimento políticopedagógico com uma formação para atuação consciente em sociedade que vise à equidade social e o desenvolvimento de um projeto popular para a sociedade brasileira.

Nesse contexto, a Educação do Campo se mostra como uma forma de resgate da dignidade dos povos do campo e da preservação de sua memória que, apesar da tentativa de esvaziamento do campo, permanecem em suas atividades e lutam por sua manutenção na área rural devendo ser valorizados e respeitados por isso, já que a área rural é vista atualmente como solução para os problemas que a sociedade enfrenta.

Podemos destacar, nos dezoito anos de desenvolvimento do movimento da Educação do Campo, os avanços legais que reconhecem e regularizam as condições imprescindíveis para que a universalização do direito a educação aconteça, levando em conta as especificidades dos indivíduos do campo:

Diretrizes Operacionais para Educação Básica das Escolas do Campo: Resolução CNE/CEB $n^{\circ}$ 
1/2002 e Resolução CNE/CEB n $2 / 2008$. Parecer $n^{\circ} 1 / 2006$ que reconhece os Dias Letivos da Alternância, também homologado pela CEB; Decreto ${ }^{\circ} 7.352$, de 4 de novembro de 2010, que dispõe sobre a Política Nacional de Educação do Campo e sobre o Programa Nacional de Educação na Reforma Agrária (Pronera). (Molina \& Freitas, 2011, p. 21).

Além desse marco legal, foi sancionado a Resolução no 40, de 26 de julho de 2011, que dispõe sobre o Programa Nacional do Livro Didático do Campo (PNLD Campo) para as escolas do campo, visando à distribuição de livro didático adequado às classes multisseriadas e às turmas seriadas do campo, buscando o melhor atendimento às necessidades educacionais desse público específico.

Porém, o direito a educação básica ainda é precário começando desde a educação infantil, negada a muitos camponeses. Segundo Vomero (2014), as crianças de 0 a 5 anos, "residentes em área rural, ainda vivem sob a distribuição desigual das políticas públicas e a dificuldade de acesso a matricula".

A situação ainda é mais crítica no ensino médio, já que muitos alunos não conseguem chegar a essa etapa. Para alguns autores, existe uma visão de que os moradores do campo não necessitam de muito estudo devido ao seu trabalho ser manual. (Santos, Silva \& Lucio, 2011, p. 2).

Entre fatos e ações existentes no cenário educacional, o que prevalece no campo são escolas de ensino fundamental de anos iniciais e, com menos frequência, ensino fundamental referente aos anos finais. São escolas, muitas vezes, multisseriadas devido ao número reduzido de alunos e em situação precárias de funcionamento. E, historicamente:

\begin{abstract}
Acredita-se que para viver na "roça" não é preciso ter muitos conhecimentos. Essa ideia mostra que para os trabalhadores do campo, ter uma formação escolar não é tão importante quanto para os que vivem na cidade. É fácil observar o descaso oferecido aos estudantes da zona rural. Suas escolas são geralmente multisseriadas, o que deixa muito a desejar quanto à eficácia do ensino lá ministrado. (Santos, Silva \& Lucio, 2011, p. 2).
\end{abstract}

Nesse contexto, a educação básica no campo não dispõe de uma estrutura física e pedagógica adequadas, os professores não tem formação apropriada para lidar com o multisseriado, nem com a necessidade de flexibilidade e ajuste social e cultural do ensino, causando danos à qualidade da educação oferecidos a população do campo. 


\section{Livro Didático na Educação do Campo}

O livro didático é uma ferramenta de auxílio ao trabalho do professor, estabelecido como direito do estudante desde a Constituição Federal de 1988, no art. 208 que estabelece a obrigatoriedade de oferta de material didático pelo governo aos alunos da rede pública e reafirmado na Lei de Diretrizes e Bases da Educação n ${ }^{\circ} 9.394$ de 20 de Dezembro de 1996, no art. $4^{\circ}$, inciso VIII.

O Programa Nacional do livro didático (PNLD) existe desde 1929, mas, com outras nomenclaturas. Seu desenvolvimento passou por mudanças durante esse tempo que abarcam um crescente aprimoramento.

O PNLD tem como objetivo distribuir às escolas públicas livros didáticos, dicionários e outros materiais que apoiem a prática educativa. Os livros didáticos disponibilizados pelas editoras são avaliados por uma comissão do Ministério da Educação (MEC), cujos resultados são divulgados nos Guias de Livros Didáticos e distribuídos para as escolas, visando orientar os professores na escolha do livro didático que será utilizado nos próximos três anos. necessidade da adequação dos livros didáticos à população do campo, pela luta do Movimento da Educação do Campo, foi sancionada a Resolução $\mathrm{n}^{\circ}$ 40 de 26 de julho de 2011 que legitimou a criação do Programa Nacional do Livro Didático do Campo (PNLD Campo) e, consequentemente, a elaboração e distribuição de livros didáticos às escolas do campo, que atendam as especificidades sociais, culturais, geográficas dos alunos e a organização seriada e multisseriada dessas escolas.

Nesse primeiro triênio, póspublicação da resolução, as coleções aprovadas para a escolha dos professores do campo foram o "Projeto Buriti Multidisciplinar" da Editora Moderna e "Girassol - Saberes e Fazeres do Campo" da editora FTD.

Buscando atender o objetivo específico de análise da política pública do livro didático do campo, recorremos a Vieira (2013) a partir de algumas das suas subcategorias de análise dos documentos oficiais do PNLD Campo, dentre elas, a relacionada à estrutura dos livros didáticos e a organização pedagógica da escola e as referências a conteúdos e sua relação com a cultura camponesa.

Através do reconhecimento da 
Compreendendo que algumas escolas do campo se organizam a partir do multisseriado, como a Escola Municipal Santa Luzia no município de Miguel Pereira no Estado do Rio de Janeiro, buscando identificar se o PNLD Campo atende a essa realidade que requer mais do que uma decisão política como tem acontecido, mas, é preciso uma decisão pedagógica que estruture as ações necessárias para que o aluno possa construir conhecimento a partir do encontro de saberes, ou seja, o que o livro apresenta para a formação a partir do contexto rural.

A partir desse pensamento, ressaltamos a seguinte citação sobre a relação entre a organização da escola do campo e a luta camponesa, presente no Guia dos Livros Didáticos do Campo 2013 (2012):

Pensando a escola nessa dinâmica, sua organização em seriada ou multisseriada, assume pouca centralidade em termos do que se espera de uma Escola do Campo. O que está em jogo é entender quais processos educativos são desencadeados na perspectiva de afirmação de identidades, do fortalecimento das lutas coletivas, da ampliação dos saberes, da compreensão e transformação da realidade, da garantia de acesso e permanência do estudante na escola e do envolvimento da mesma com as questões do contexto a sua volta. (Brasil, 2012, p. 11).
Considerando o trecho anterior, percebemos que os princípios que tratam o PNLD Campo estão em consonância com a lógica que direciona a luta dos movimentos por uma Educação do Campo, mas, que desconsideram a organização pedagógica como requisito para que os objetivos de afirmação de identidades e transformação da realidade aconteçam de forma plena.

De acordo com a Resolução $n^{\circ} 40$, de 26 de julho de 2011, a produção do livro didático deve levar em conta as "classes multisseriadas e seriadas do campo para melhor atendimento às necessidades educacionais de públicos específicos". É necessário que haja uma articulação entre os princípios sociais e políticos da Educação do Campo e a organização pedagógica multisseriada para que, como afirmam Druzian e Meuer (2013), essa organização tornese uma possibilidade de inovação metodológica. Não é admissível ignorar a realidade complexa e difícil da turma multisseriada num projeto de transformação da escola para a construção de um novo projeto de sociedade.

Outro aspecto considerado na pesquisa diz respeito aos conteúdos presentes nos livros didáticos do campo. 
Buscamos aprofundar a análise do PNLD Campo a partir da reflexão sobre a coleção escolhida pela Escola Municipal Santa Luzia, o Projeto Buriti Multidisciplinar da Editora Moderna.

No item Visão Geral, do Guia dos Livros Didáticos do Campo 2013, podemos perceber, inicialmente, que essa obra inclui questões mais específicas da Educação do Campo apenas nos volumes dois e três. Tem como principal ponto fraco as "Tentativas pontuais, nos volumes 1, 4 e 5, de incluir questões específicas da educação do campo nas atividades". (Brasil, 2012, p. 35).

Essa afirmação é ratificada no item Análise da Obra - Proposta para Educação do Campo, quando se identifica "tentativas" de aproximação com as especificidades do campo que não podem ser confirmadas com consistência.

Dessa forma, ao destacarmos o principal objetivo do PNLD Campo que é a distribuição de livros didáticos para as escolas públicas do campo de ensino fundamental I (anos iniciais) que considerem as "especificidades do contexto social, econômico, cultural, político, ambiental, de gênero, geracional, de raça e etnia dos Povos do Campo". (Brasil, 2012, p. 8), e o comparamos com a avaliação feita do livro Projeto Buriti Multidisciplinar, identificamos que existe uma contradição quanto ao que se espera do livro para a Educação do Campo e o que foi aprovado.

Entendemos que a disponibilidade desse livro, que se aproxima de forma pontual e restrita com a realidade do campo, pode esconder uma falsa adequação das escolas às vivências do homem do campo e pode acarretar limitações nas possibilidades de fortalecimento da identidade e da cultura camponesa, bem como da luta por seus direitos. Essa afirmação leva em consideração o uso do livro como principal fonte de informações, entendendo que o mesmo não consegue atender a diversidade de situações culturais, sociais e naturais sobre a Educação do Campo na essência, ou seja, que a mesma não é uniforme, única, tão pouco a mesma na sua construção histórica no país.

\section{Livro Didático na Escola Municipal Santa Luzia}

Buscamos conhecer o funcionamento e a estrutura da Escola Municipal Santa Luzia e a realidade social, econômica e cultural das crianças do Vale das Princesas, bairro 
onde se localiza a escola, entendendo como integrado à realidade global, mas, que guarda especificidades de zona rural do município e região, para melhor compreender a dinâmica educativa da escola estudada e do livro didático nesse cenário fluminense.

A Escola Municipal Santa Luzia localiza-se na zona rural do município de Miguel Pereira, no Estado do Rio de Janeiro, a aproximadamente $33 \mathrm{~km}$ de distância do centro da cidade. Ao contrário do que observamos na pesquisa bibliográfica sobre Educação do Campo, a Escola Municipal Santa Luzia possui infraestrutura adequada ao número de alunos atendidos, que atende atualmente (2016) o número de seis (6) alunos.

A escola possui duas salas de aula, refeitório acoplado a cozinha, dois banheiros, uma sala de informática e uma biblioteca adaptada funcionando junto à secretaria, que segue as normas da Secretaria de Educação Básica do Ministério da Educação (MEC).

A escola possui duas funcionárias: a professora e a merendeira, e funciona apenas no turno da manhã. A diretora da instituição coordena o pólo da região composto por mais duas escolas, localizado na Escola Municipal Felício
Bastos, também no município de Miguel Pereira.

Para compreendermos as relações desenvolvidas entre as crianças que a Escola Municipal Santa Luzia atende e o espaço do campo, entendido como as condições físicas, sociais e culturais, precisamos conhecer seus modos de vida a partir de suas rotinas. Vivenciadas como "ações que se repetem no dia a dia; sua regularidade permite compreender o modo de vida das pessoas". (Caldart, Paludo \& Doll, 2006, p. 110).

Para o estudo exploratório desses dados utilizou-se de entrevista livre em diálogo narrativo realizada com as crianças da escola no dia 04 de maio de 2015, e buscamos relacioná-la com a entrevista realizada anteriormente com a professora da escola.

De acordo com essa entrevista, a vida das crianças se divide entre os momentos da escola, as atividades de rotina e colaboração com seus pais em casa e as brincadeiras que perpassam esse segundo momento do cotidiano escolar.

As crianças tem contato não só com animais de estimação, como as crianças do bairro, mas, convivem diariamente com animais como porcos, galinhas, cavalos, bois, etc., e têm 
conhecimentos de como lidar com esses animais, em sintonia com o contexto vivido. Eles também estão integrados as práticas sociais e históricas da comunidade através do artesanato que é realizado em cooperativa pelas suas mães, denominada "Mulheres de Fibra".

Assim, podemos perceber que crianças desta comunidade escolar têm vivências diferentes e que influenciam a sua leitura de mundo, como amplamente trabalhado pelo educador Paulo Freire. Seus conhecimentos e saberes culturalmente produzidos são a base para o processo de novos saberes, e que o livro didático e principalmente a escola devem levar em conta na hora da aprendizagem.

Nesse contexto de saberes prévios, o livro didático do campo atende as especificidades dos alunos da Escola Municipal Santa Luzia? É relevante para suas aprendizagens?

Para respondermos essas perguntas realizamos questionários semiestruturados com os sujeitos (professora e alunos) envolvidos com os processos de aprendizagem na escola pesquisada e analisamos esses dados com base na pesquisa bibliográfica do tema em destaque (Vieira, 2013; Oliveira, 2014; Molina \& Freitas, 2011; Pino, 2010).
O primeiro questionário foi realizado no dia 10 de dezembro de 2014 com a professora da instituição, com o objetivo de identificar se o livro didático do campo atendia, ou não, a realidade vivida pela comunidade da Escola Municipal Santa Luzia. Chegamos à conclusão de que a escola recebe todos os anos livros didáticos consumíveis ${ }^{\mathrm{i}}$, que são usados para algumas atividades nas turmas atendidas pela escola. Esses livros, segundo a professora, não atendem plenamente a realidade vivida pelos alunos, sendo difíceis de entender em alguns casos, dependendo da criança, como por exemplo, fora de algumas vivências do campo de seus alunos e são, muitas vezes, substituídos por outros recursos didáticos que melhor exemplificam as necessidades dos alunos e a própria metodologia da professora, como os desenhos, livros de literatura, jornais e materiais trazidos pela própria comunidade, possibilitando maior proximidade com as famílias, favorecendo a compreensão das crianças. A percepção contextualizada da professora e a possibilidade de integração com outros materiais garante a utilização do livro didático no cotidiano escolar, em sintonia com o tempo de aprendizado de cada criança. 
Realizamos uma segunda entrevista com a professora no dia 4 de maio de 2015. Nessa entrevista a professora afirma que o livro didático utilizado na escola é de difícil compreensão em algumas unidades, porém, reconhece que ele se relaciona com a vida das crianças, o que facilita a identificação cotidiana do aluno com os conceitos.

Sabemos que essa compreensão também passa pela própria professora, que precisa ter orientação e formação permanente para o pleno exercício da docência no contexto no qual ela mesma está inserida. Isso não quer dizer ser refém de formação continuada ou coisa parecida, mas, organizar uma prática pedagógica que leve em consideração os diferentes olhares e percepções das diversas linguagens e possibilidades existentes no cotidiano escolar.

Através do questionário, podemos perceber que a professora desconhece o movimento de Educação do Campo e seus pressupostos, podendo em alguns casos dificultar a implantação de um (outro) projeto de educação que favoreça a classe trabalhadora camponesa. Entretanto, tem plena posição pedagógica e política em relação ao papel social da escola para a formação de crianças e jovens que lutem por direitos coletivos e melhorias para a comunidade. A professora reside no Vale das Princesas, nasceu e foi criada no contexto social e cultural das crianças, respeitando o período histórico.

Quando perguntada sobre o motivo da sua posição contrária a apenas um material didático específico para o campo, afirma que os alunos irão um dia para a cidade, realidade que ela vivencia e que vai reforçando ainda mais a importância do uso contextualizado do livro didático do campo, que requer uma intervenção deliberada da professora para aproximar seus conteúdos às vivências da região e também ao movimento real de migração do campo para a cidade que, solidificou-se na possibilidade de interpretação da professora, a necessidade mesmo no contexto do campo de oportunizar ao aluno uma formação universal nas diversas áreas de conhecimento, o que é garantindo na constituição de 1988 e na Lei de Diretrizes e Bases da Educação Nacional (LDBEN) de 1996.

Sabemos que esse movimento de luta pela fixação no campo, que passa pelo acesso a terra, tem na escola o seu principal aliado, de transformação para outra escola, para as novas gerações de 
brasileiros que tem o direito de produzir conhecimentos não só sobre a sua realidade, como também de compreender o mundo em que vive.

A postura da professora aponta para a concretização da luta política iniciada pelos movimentos sociais do campo em favor de seus direitos. Como afirma Molina e Freitas (2011) o professor deve estar comprometido com os ideais da luta por igualdade e favorecer que o auxílio do livro didático tenha efeito, por uma nova atitude dos e pelos sujeitos do campo.

O bom livro didático não só consegue atingir os alunos em sua apresentação de conceitos como também oferece o desafio de pensar o mundo em diferentes escalas, formas e funções, seja da sua escola, do seu bairro, do país ou do funcionamento do mundo. Sabemos que viver na área urbana é diferente de viver na área rural. Entretanto, estamos falando de garantir com a escola a possibilidade de compreender a organização do lugar que vivemos a partir de conceitos encontrados muitas vezes apenas naquele lugar, por isso, é importante estabelecer critérios de diálogos (campo e cidade) com a construção de um currículo escolar que ofereça essa oportunidade na vida escolar das crianças.

Esse debate por mudança, por uma nova maneira de trabalhar com os livros didáticos com e na escola, pode ser exemplificado por Oliveira, ao dizer: “o auxílio que o livro didático oferece ao aluno através de seus conteúdos precisa ser absorvido da forma correta, caso contrário não terá grande influência na vida social do aluno". (Oliveira, 2014, p. 7).

\section{Considerações Finais}

Podemos compreender que a Educação do Campo, bem como as conquistas na melhoria de sua qualidade, são frutos das pressões dos movimentos sociais do campo para a efetivação de seus direitos frente ao governo e políticas sociais, que por sua vez, tem desenvolvido mecanismos legais de políticas públicas para a concretização desses direitos.

Uma dessas políticas diz respeito ao livro didático específico para a realidade do campo, que tornou possível vivenciar essa experiência na Escola Municipal Santa Luzia em Miguel Pereira no Estado do Rio de Janeiro.

Percebemos que a ancoragem cultural dos conteúdos no contexto da comunidade é requisito indispensável 
para aprendizagem dos alunos e sua correta compreensão nas diversas escalas de entendimento do mundo. Nesse sentido, considera-se a importância da definição e articulação dos conteúdos da aprendizagem com as vivências e experiências dos alunos do campo integrados com os livros didáticos e outras ferramentas pedagógicas, ampliando as relações entre a cidade e o campo, para que dessa forma as crianças possam dar sentido à produção de saberes e terem uma formação crítica para atuação em sociedade, de pertencimento ao vivido, valorizando suas emoções e desejos com a terra.

Considerando a realidade pesquisada no Vale das Pedrinhas em Miguel Pereira, podemos dizer que o livro didático formulado para as escolas urbanas não atendem plenamente as especificidades dos alunos do campo, sendo necessários adaptações e o uso de outras ferramentas pedagógicas para melhor desenvolvimento por parte da comunidade escolar.

Assim, podemos afirmar que o livro didático da coleção projeto Buriti Multidisciplinar não se relaciona plenamente com o mundo vivido, desejado, sonhado pelos alunos a que se destina. Pode favorecer em alguns casos a alienação dos alunos quanto a sua relação com o espaço urbano e com o mundo a sua volta e, consequentemente, afeta a função social da escola, tornando a escola um grande espaço de reprodução da nossa própria história, com amplo viés doutrinador de corpos e mentes pela elite desse país, tradicionalmente concentrada nas regiões urbanas.

Identificamos também, a dificuldade de produzir obras que atendam a heterogeneidade do campo, apesar de importante para a comunidade. De certa forma, o Programa Nacional de Livro Didático para o Campo ainda necessita de constantes melhorias, principalmente, na abordagem conceitual entre a cidade e campo. Segundo o Guia dos Livros Didáticos do Campo (2013), das dezesseis coleções avaliadas, duas foram aprovadas, mostrando que há um longo caminho a ser percorrido para a produção de obras de qualidade que atendam a um projeto diferenciado de educação.

\section{Percebemos que apesar do PNLD} Campo ter como objetivo distribuir obras que atendam a especificidade do campo, as obras aprovadas não necessitavam levar em conta a organização multisseriada, nem se 
relacionar de forma pertinente ao contexto camponês nas suas lutas, formas de reprodução da existência, identidade e cultura. A partir de tal constatação é imprescindível à continuação desse estudo, para que a escola do campo não se torne, mais uma vez, vítima de políticas públicas paliativas que só servem para silenciá-lo de reivindicações das populações do campo.

Aliado a produção das obras que devem valorizar mais a cultura camponesa, percebemos que o professor desempenha um papel fundamental nas escolas do campo. Professores que em muitos casos não têm a formação específica para atuarem com a Educação do Campo e que desconhecem o papel da escola na vida da população do campo, e não conseguem explorar as possibilidades de um livro didático específico na articulação da cultura camponesa e os conhecimentos científicos do mundo em que vivemos, tanto na cidade como no campo.

Defendemos aqui não só o aprimoramento da política pública do livro didático, ampliando para outros materiais de forma integrados ao uso do livro, mas, também uma política de formação inicial e continuada aos professores do campo para que eles possam estar preparados para a organização escolar multisseriada e para a utilização do livro didático a partir de uma atuação autônoma e comprometida com as lutas da população do campo e com a transformação da escola tradicional em escola do campo, a partir do conceito construído pelos movimentos sociais do nosso país.

\section{Referências}

Brasil. (1988). Constituição 1988. Constituição da República Federativa do Brasil: promulgada em 5 de outubro de 1988. Disponível em: $<$ http://www.planalto.gov.br/ccivil_03/c onstituicao/constituicao.htm> Acesso em: 06/05/2015.

Brasil. (2010). Decreto $n^{\circ} 7.084$, de 27 de Janeiro de 2010. Disponível em:< http://www.planalto.gov.br/ccivil_03/ Ato20072010/2010/Decreto/D7084.htm>. Acesso em 10/12/2014.

Brasil. (2011). Edital de convocação para o processo de inscrição $e$ avaliação de obras didáticas para o Programa Nacional Do Livro Didático Do Campo PNLD Campo 2013 - Edital de convocação 05/2011. Disponível em: $<$ http://www.fnde.gov.br/programas/livr o-didatico/livro-didatico-editais $>$

Acesso em 10/12/2014.

Brasil. (2012). Guia de livros didáticos: PNLD Campo 2013: Guia de Livros. Brasília: Ministério da Educação, Secretaria de Educação Continuada, Alfabetização, Diversidade e Inclusão. Disponível em: <http://www.fnde.gov.br/programas/livr 
o-didatico/livro-didatico-apoio-agestao> Acesso em: 10/12/2014

Brasil. (2009). Plano Municipal de Educação. Secretaria de Educação Cultura e Esporte Miguel Pereira.

Brasil. (2015). Plano Municipal de Educação. Secretaria de Educação Cultura e Esporte, Miguel Pereira (Em andamento). Disponível em: <http://www.pmmp.rj.gov.br/files/cham amento/IChamamento_Publico_PME_F ORMATADO_14_05.pdf.> Acesso em 30/11/2015.

Brasil. (2011). Resolução $n^{o} 40$, de 26 de julho de 2011. Disponível em: <http://www.fnde.gov.br/fnde/legislaca o/resolucoes/item/3463resolu\%C3\%A7\%C3\%A3o-cd-fnden\%C2\%BA-40-de-26-de-julho-de2011.>. Acesso em 10/12/2014.

Caldart, R. S. (2002). Por uma Educação do Campo: Traços de uma identidade em construção. In Kolling, E. J., Cerioli, P. R., \& Caldart, R. S. (Orgs.). Educação do Campo: identidade e políticas públicas. Brasília, DF: Articulação Nacional Por Uma Educação do Campo. Coleção Por Uma Educação do Campo, (4). Disponível em:<http://www.forumeja.org.br/.../Vol $\% 204 \%$ 20Educação\%20Básica\%20do\% 20.> Acesso em: 17/11/2015.

Druzian, F., \& Meurer, A. C. (2013). Escola do campo multisseriada: experiência docente. Geografia Ensino \& Pesquisa, 17(2), 129-146.

Fernandes, B. M. (2002). Diretrizes de uma caminhada. In Kolling, E. J., Cerioli, P. R., \& Caldart, R. S. (Orgs.). Educação do Campo: identidade $e$ políticas públicas. Brasília, DF: Articulação Nacional Por Uma Educação do Campo. Coleção Por Uma Educação do Campo, (4). Disponível em: $<$ http://www.forumeja.org.br/.../Vol \%204\%20Educação\%20Básica\%20do\% 20.> Acesso em: 17/11/2015.

Ferreira, F. J., \& Brandão, E. C. (2011). Educação Do Campo: Um Olhar Histórico, Uma Realidade Concreta. Revista Eletrônica de Educação. (9).

Henriques, R. (Org.). (2007). Educação do Campo: diferenças mudando paradigmas. Cadernos SECAD 2. Secretaria de Educação Continuada, Alfabetização e Diversidade. Brasília DF.

Lajolo, M. (1996). Livro didático: um (quase) manual de usuário. Em Aberto, (69). Disponível em: 〈http://emaberto.inep.gov.br/index.php/ emaberto/article/view/1033/935>Acesso em 04/12/2015.

LDBEN. (1996). Lei de Diretrizes $e$ Bases da Educação Nacional. Brasília: Ministério da Educação.

Ludke, M., \& André, M. E. D. A. (2013). Pesquisa em Educação: Abordagens Qualitativas. Rio de Janeiro: GEN.

Molina, M. C., \& Freitas, H. C. A. (2011). Avanços e desafios na construção da educação do campo. Em Aberto, 24(85), p. 17-31.

Oliveira, J. P. T. (2014). A eficiência e/ou ineficiência do livro didático no processo de ensino-aprendizagem. In $I V$ congresso ibero-americano de política e administração da educação/ VII congresso Luso-Brasileiro de política e administração da educação. Porto: Escola Superior de Educação do Politécnico do Porto. Disponível em: <http://scholar.google.com.br $>$ Acesso em: 09/03/2015. 
Pino, A. (2010). A criança e seu meio: Contribuições de Vygotsky ao desenvolvimento da criança e à sua Educação. Psicologia USP, 21(4), 741756.

Portal do FNDE. (2015). Programa Nacional do Livro Didático. Disponível em: $\leq$ http://www.fnde.gov.br/programas /livro-didatico/livro-didaticoapresentacao>Acesso: 28/08/2015.

Caldart, R. S., Paludo, C., \& Doll, J. (2006). Como se formam os sujeitos do campo? Idosos, adultos, jovens, crianças e educadores. Brasília: PRONERA: NEAD.

Projeto Buriti Multidisciplinar. (2012). Obra coletiva. Editora responsável: Marisa, Martins Sanchez. São Paulo, Editora Moderna.

Santos, E. F., Silva, J. M., \& Lúcio, A. B. (2011). O descaso da educação do/no campo: as dificuldades enfrentadas por professores e alunos da escola no campo no interior de alagoas (um estudo de caso). Revista Homem, Espaço $e$ Tempo. Disponível em: $\leq$ http:// dspace.c3sl.ufpr.br/.../R\%20\%20D\%20-\%20EDILAINE\%20>

Acesso em: 26/07/2014.

Vieira, E. A. (2013). Livros Didáticos para Escolas do Campo: Aproximações A partir do PNLD Campo-2013. Curitiba. Disponível em: $<$ http://dspace.c3sl.ufpr.br/.../R\%20\%20D\%20-\%20EDILAINE $>$ Acesso em: $15 / 11 / 2015$.

Vomero, M. F. (2014). O espaço dos pequenos. Revista Educação. 207. Disponível em: <http://revistaeducacao.uol.com.br/texto s/207/a-voz-do-campo-318118-1.asp >Acesso em: 02/12/2015. i "Entende-se por livros didáticos consumíveis aqueles entregues para utilização dos alunos e professores, que passam a ter sua guarda definitiva, sem necessidade de devolução ao final de cada período letivo" - Edital de convocação 05/2011.

Recebido em: 05/10/2016

Aprovado em: 19/10/2016

Publicado em: 13/12/2016

Como citar este artigo / How to cite this article / Como citar este artículo:

APA:

Costa, M. L., \& Cabral, C. L. O. (2016). Da Educação Rural à Educação do Campo: uma luta de superação epistemológica/paradigmática. Rev. Bras. Educ. Camp., 1(2), 476-494.

ABNT:

COSTA, M. L.; CABRAL, C. L. O. Da Educação Rural à Educação do Campo: uma luta de superação epistemológica/paradigmática. Rev. Bras. Educ. Camp., Tocantinópolis, v. 1, n. 2, p. 476-494, 2016. 